\title{
A Novel 3D PILA-Type UHF RFID Tag Antenna Mountable on Metallic Objects for IoT Indoor Localization
}

\author{
Mondher Dhaouadi $\mathbb{I D}^{1,2}$ and Fethi Choubani $\mathbb{D}^{1}$ \\ ${ }^{1}$ University of Carthage, Higher School of Communication of Tunis (Sup'COM), LR11TIC03 Innov'COM Laboratory, \\ Ariana 2083, Tunisia \\ ${ }^{2}$ University of Gabes, Higher Institute of Informatics and Multimedia of Gabes (ISIMG), Gabes, Tunisia \\ Correspondence should be addressed to Mondher Dhaouadi; mondher.dhaouadi@supcom.rnu.tn
}

Received 1 May 2021; Revised 1 September 2021; Accepted 9 September 2021; Published 27 September 2021

Academic Editor: Symeon Nikolaou

Copyright (c) 2021 Mondher Dhaouadi and Fethi Choubani. This is an open access article distributed under the Creative Commons Attribution License, which permits unrestricted use, distribution, and reproduction in any medium, provided the original work is properly cited.

\begin{abstract}
In this paper, a novel 3D planar inverted-L antenna (PILA) Ultrahigh Frequency (UHF) Radio Frequency Identification (RFID) tag mountable on metallic surfaces is proposed for the Internet of Things (IoT) indoor localization applications. The proposed tag antenna $(45 \mathrm{~mm} \times 82 \mathrm{~mm} \times 4 \mathrm{~mm}$ or $0.137 \lambda \times 0.25 \lambda \times 0.012 \lambda)$ is designed for mounting on metallic objects. The 3D PILA antenna is fabricated using a copper sheet of thickness $1 \mathrm{~mm}$ and air as the dielectric substrate in order to minimize costs for materials and realization. In the design, T-slot has been inserted in the radiating element for tuning of the tag's resonance for achieving good matching with the chip. Also, a simple equivalent circuit model has been obtained to analyze the impedance of the 3D PILA. Based on the optimized design, the fabricated prototype has been measured in the anechoic chamber. The resonant frequency of the proposed tag is stable, and it is not affected much by the metallic object. The measurement results of the antenna prototype demonstrated a reasonable agreement with the simulation results, and a read range of $3.6 \mathrm{~m}$ was measured inside an anechoic chamber. Most importantly, in the building hallway, the proposed tag is able to achieve a maximum read distance of $18 \mathrm{~m}$ with a transmitted power of $31.5 \mathrm{dBm}$ at $867 \mathrm{MHz}$ when placed on metal. With the 3D PILA antenna structure, the proposed antimetal tag is a suitable solution that can be integrated into an indoor localization scenario.
\end{abstract}

\section{Introduction}

Indoor localization systems have attracted research interest during the last decade due to their various application [1]. However, indoor positioning techniques are among the most challenging issues related to the Internet of Things (IoT). IoT system is the result of the integration of several technologies, including sensing and methods for identification. Radio Frequency Identification (RFID) and wireless sensor networks (WSNs) are the most important blocks in the framework of the IoT [2]. In IoT, RFID technology is used in smart cities applications such as cameras, human tracking, smart parking, GPS (global positioning system), and intelligent sensors. The RFID system is an identification technology, automatically and in real time, capturing and transmitting data to identify objects through reflected radio waves [3, 4]. However, since UHF RFID tags are directly mounted on or near metallic objects, the presence of metal objects in contact or close proximity to the tag can essentially degrade the impedance matching, radiation pattern, radiation efficiency, gain, bandwidth, and read range of the tag. In the past few years, several methods have been proposed by different researchers to tackle and overcome this problem by enhancing the tag's performance. In $[5,6]$, inserting a ceramic material between the tag and metallic object has been proposed. However, using ceramics can increase the costs significantly. The artificial magnetic conductor (AMC) ground and an electromagnetic bandgap (EBG) structure are also used for isolating the RFID tags from metal surfaces $[7,8]$. However, applications of the AMC and EBG structures can help improve the gain and the read range, but they introduce higher fabrication costs and increase the tag size. The other approach is based on the design of planar antennas with an 
open stub feed for designing on-metal tags [9]. However, the patch resonator with open stub is large in size for antenna design. To achieve miniaturization, metallic vias are used for shorting one edge of the radiating patch to the ground plane to form new antenna structures such as meandered patch antenna with short stub mountable on metallic objects [10]. In recent years, new techniques have been explored for reducing the planar patch size. To achieve compact size, a flexible patch antenna in [11] was designed using the serration technique and was able to achieve read distances of $7 \mathrm{~m}$ when attached to a $20 \mathrm{~cm} \times 20 \mathrm{~cm}$ metal plate. To further reduce the patch antenna size, the folding method has recently been proposed for designing various flexible RFID tags for on-metal applications [12-15]. As the size reduces, there is an increase in ohmic losses, consequently affecting the antenna performances such as gain, efficiency, and directive radiation.

The planar inverted-F antenna (PIFA) using the metallic surface as ground plane is a popular structure for designing miniature metal tags. By applying the PIFA design concept, the antenna size can be easily reduced by introducing vias $[16,17]$, but the performance of a PIFA is significantly more sensitive to the position of the vias [18]. In this paper, a new type of L-shaped antenna is used for designing a novel 3D tag antenna that can be mounted on a metal object for IoT RFID applications. The proposed 3D PILA tag without substrate does not require the use of vias to achieve the antenna design, which reduces the cost of the manufacturing process. This paper is organized in the following way: in Section 2, the antenna configuration is explained and an equivalent circuit is developed to describe the input impedance of the proposed 3D PILA. In Section 3, experimental results are described. Finally, conclusions are provided in Section 5.

\section{Configuration and Equivalent Circuit}

2.1. Antenna Structure Design. The configuration of the PILA used for this study is a well-known antenna because it has many outstanding advantages like simple structure, small size, lightweight, easy method fabrication, and low manufacturing cost. The configuration of the proposed $3 \mathrm{D}$ tag antenna is shown in Figure 1. The prototype UHF RFID tag antenna has been realized in an overall volume of $45 \times 82 \times 4 \mathrm{~mm}^{3}$. It consists of a rectangular patch with a $\mathrm{T}$-slot cut at the center. The antenna consists of two-layer thin copper with a thickness of $t_{s}=1 \mathrm{~mm}$, separated by air. To minimize the antenna size, a shorting plate is used to connect the top radiating patch to the ground plane. The shorting stub is in direct contact with one side of the patch.

To design a UHF RFID tag, the impedance $\left(Z_{a}\right)$ of a tag antenna should be conjugate to the chip impedance $\left(Z_{c}\right)$ of the tag. Tag antenna is first simulated and optimized with the electromagnetic (EM) simulation software CST Microwave Studio by monitoring the complex impedance matching, return loss, and tag reading range to better understand the behavior of the tag. If the tag satisfies all of these requirements, the antenna design is done. Otherwise, the design is further modified to achieve a high level of optimization until requirements are met.
The microchip selected for integrating with the proposed PILA tag antenna is an Alien Higgs-3 RFID IC (from Alien Corporation's). The equivalent circuit is a parallel RC-circuit with resistance $\mathrm{Rp}=1500 \Omega$ and capacitance $\mathrm{Cp}=0.85 \mathrm{pF}$ [19]. The antenna is matched to the RFID chip by means of a very simple matching based on a T-slot. The T-slot has been inserted in the radiating element for tuning of the tag's resonance. The slot antenna transforms the capacitive impedance of the PILA antenna to inductive. This slot achieves complex conjugate impedance matching between the antenna and capacitive tag IC for achieving good adaptation matching with the chip to obtain a good gain in the frequency in resonance. Table 1 shows the optimized design parameters of the proposed 3D PILA antenna structure.

However, the matching polarization of the PILA tag and reader antenna affects the communication link. So, both antennas are linearly polarized, and the read performance is dominated by the alignment between the electric fields of the reader and tag antennas. More specifically, our PILA tag should be kept in the right position to be able to be read and written.

2.2. Equivalent Circuit Model. The equivalent circuit model of the proposed 3D PILA tag is derived for analyzing its input impedance. The equivalent circuit model is shown in Figure 2 . To build the model, the top radiating patch is represented by the resistance $\left(R_{a}\right)$, inductance $\left(L_{a}\right)$, and capacitance $\left(C_{a}\right)$ in a parallel RLC circuit. As can be seen in Figure 1 , the radiator and the ground plane function like a parallel plate capacitor and its capacitance $C_{a}$ [20] can be estimated using the following equation:

$$
C_{a}=\frac{\varepsilon_{0} A_{e}}{h}
$$

where $A_{e}=W L_{3}-W_{1}\left(L_{2}+L_{1}\right)$ is the effective surface area (by removing the $\mathrm{T}$-slot) of the radiator and $\varepsilon_{0}=8.854 \times$ $10^{-12} \mathrm{~F} / \mathrm{m}$ is the permittivity of free space. The resistance $R_{a}$, which is needed to account for radiation and loss resistances, and inductance $L_{a}$ of the $L$-shaped patch can be determined using the CurveFit macro model [21]. With reference to Figure 2, the stub is represented by the inductance $\left(L_{s}\right)$ and resistance $\left(R_{s}\right)$ placed in series. By knowing the stub dimension, its inductance $L_{a}$ (in $\mathrm{nH}$ ) $[22,23]$ can be calculated using the following equation:

$$
L_{s}=200 L_{4}\left[\ln \left(\frac{2 L_{4}}{h+t_{s}}\right)+0.50049+\frac{h+t_{s}}{3 L_{4}}\right],
$$

where $t_{s}=1 \mathrm{~mm}$ denotes the copper thickness of the stub. Also from the stub dimension, the resistance of the stub can be estimated using the $\mathrm{AC}$ resistance:

$$
R_{s}=2\left[\frac{\rho L_{4}}{h t_{s}}\right]\left[\frac{K_{c}}{1-e^{-x}}\right],
$$

where $x=2\left(1+t_{s} / h\right)\left(\delta / t_{s}\right), \quad \delta=2.2 \times 10^{-6} \mathrm{~m}$ is the skin depth of copper, $\rho=1.72 \times 10^{-8} \Omega \mathrm{m}$ is the copper resistivity, and $K_{c}=2.084$ is the current crowding factor [12]. The inductance of the shorting wall is estimated using $L_{\mathrm{sst}}=2 L_{\mathrm{s}}$. 


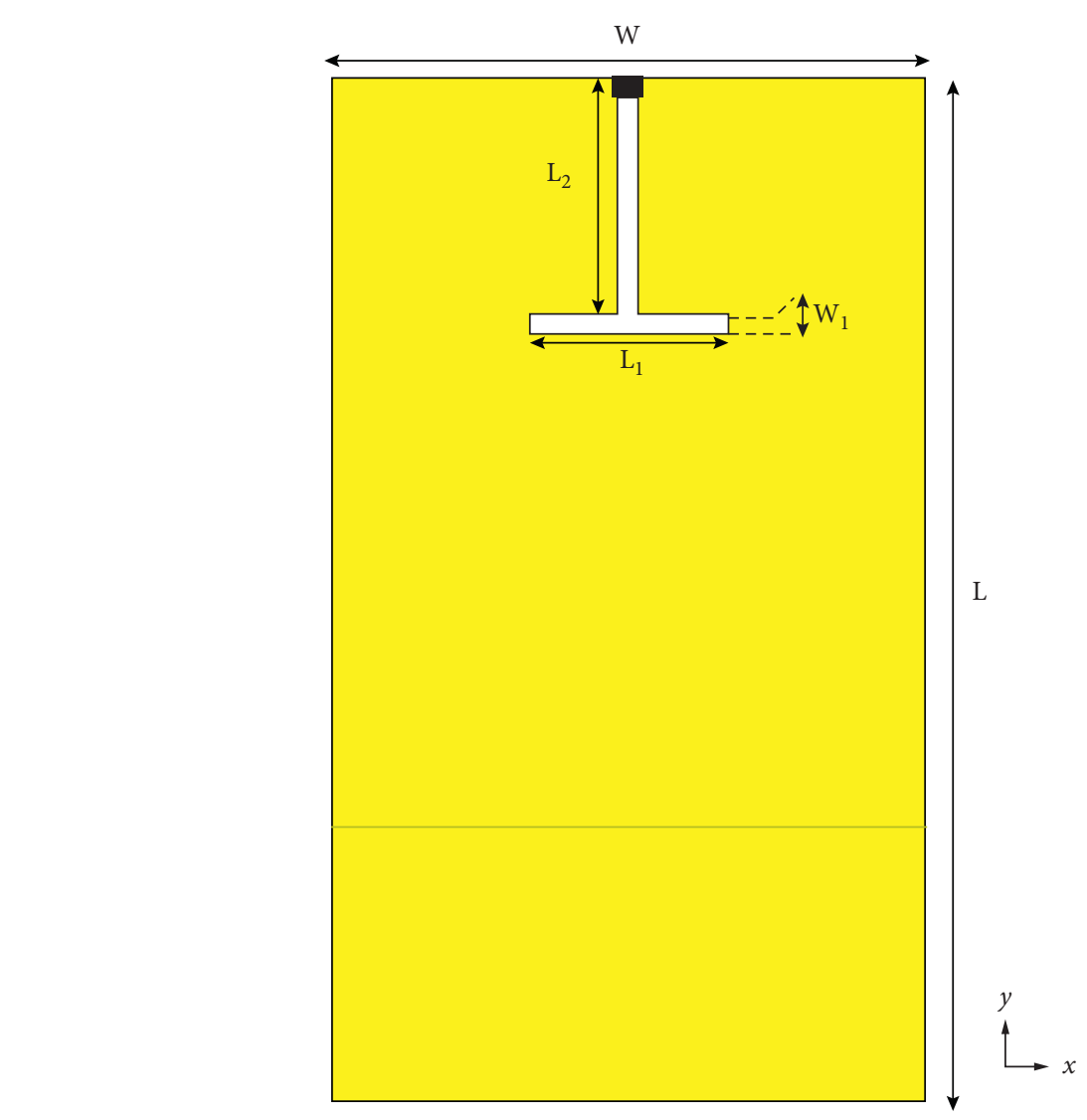

(a)

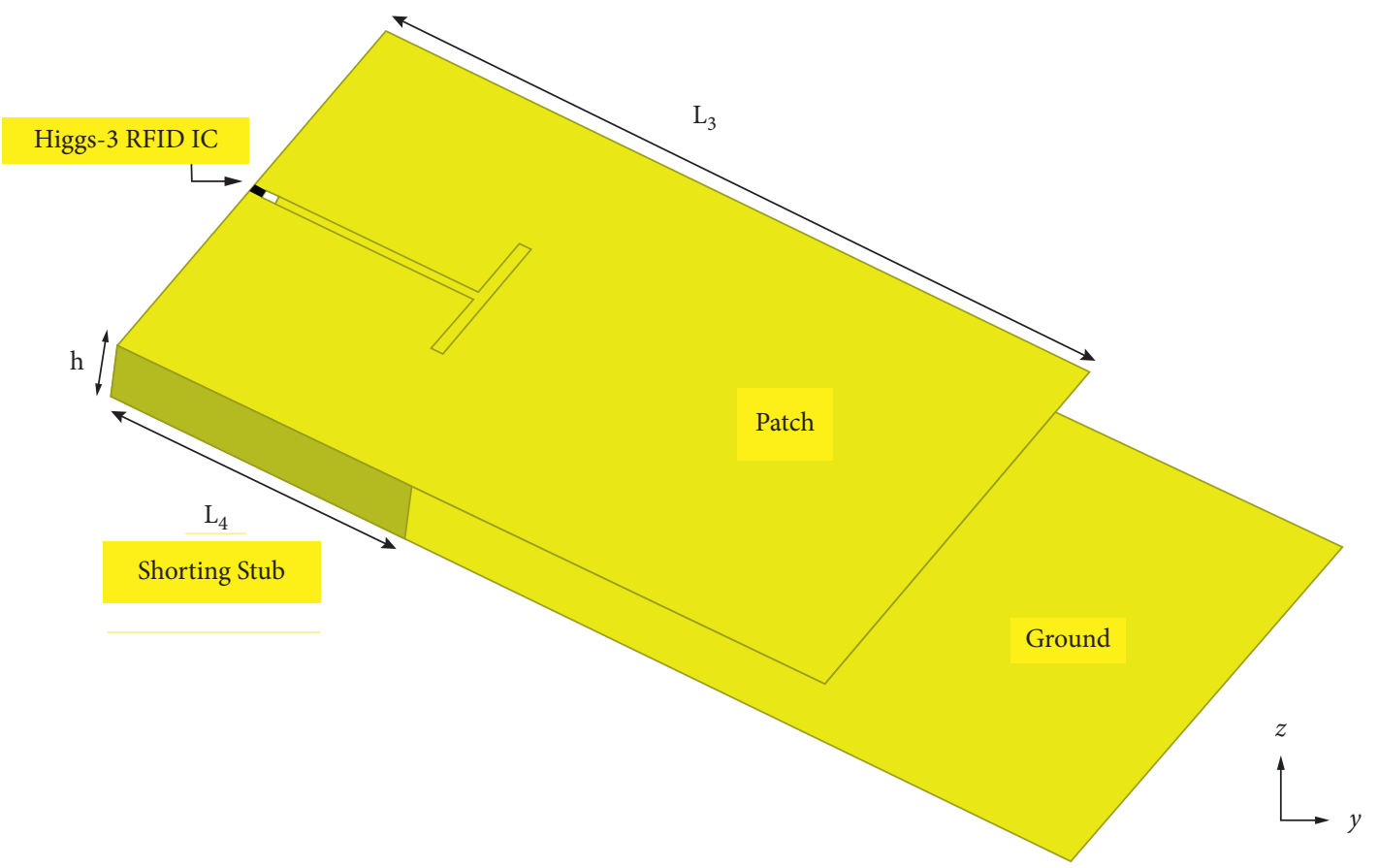

(b)

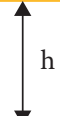

(c)

Figure 1: Continued. 


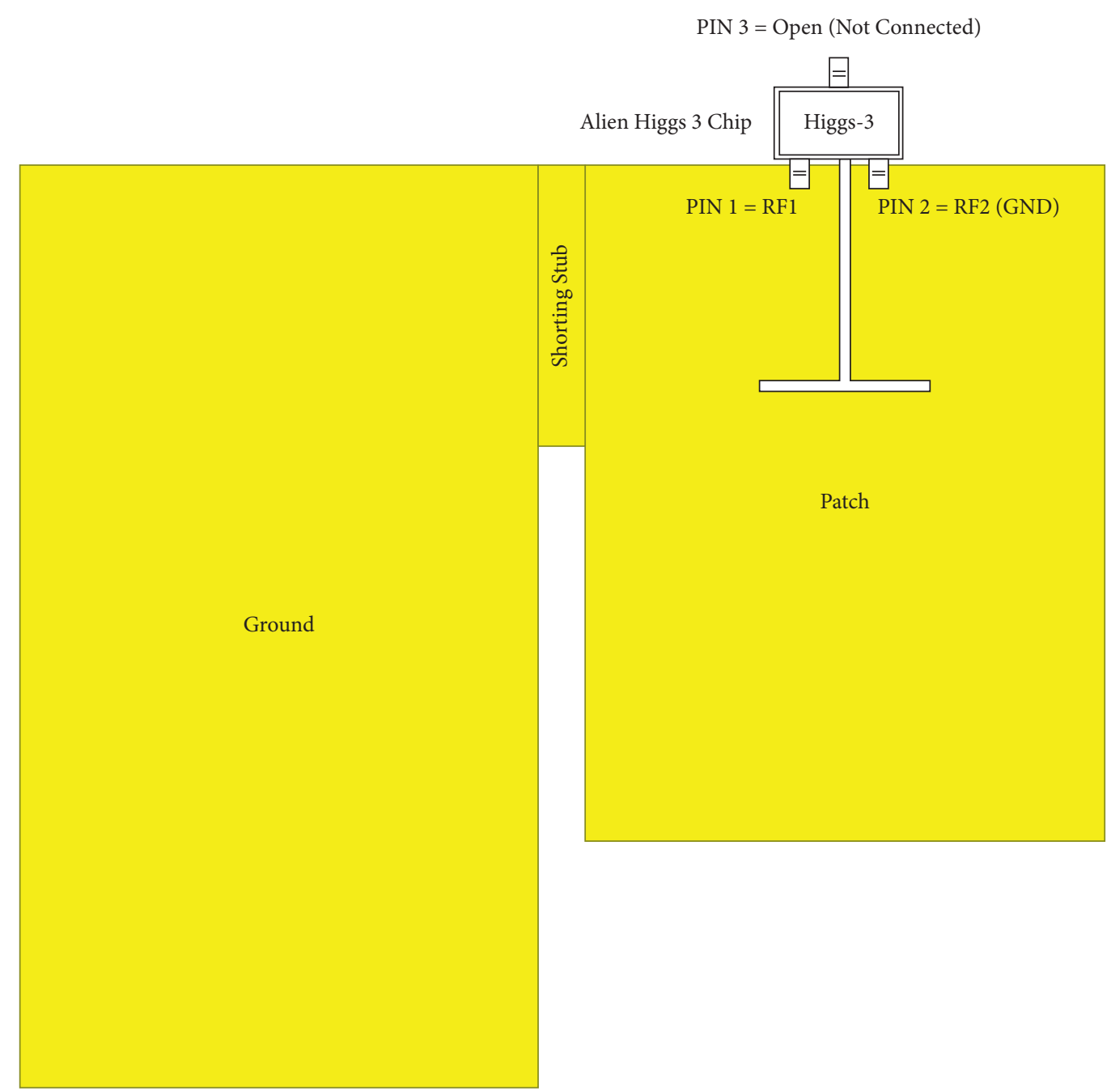

(d)

Figure 1: Configuration of the proposed tag: (a) top layer, (b) isometric view, (c) side view, and (d) PILA tag antenna with an RFID chip attached.

TABLE 1: Optimized design dimensions of the proposed 3D PILA antenna.

\begin{tabular}{lc}
\hline Parameter & Dimension $(\mathrm{mm})$ \\
\hline$W$ & 45 \\
$W_{1}$ & 1 \\
$L$ & 82 \\
$L_{1}$ & 15 \\
$L_{2}$ & 19 \\
$L_{3}$ & 60 \\
$L_{4}$ & 25 \\
$h$ & 4 \\
\hline
\end{tabular}

The capacitance $\left(C_{g}\right)$ of the T-slot gap [23] that accommodates the chip can be calculated using the following equation:

$$
C_{g}=\frac{\varepsilon_{0}\left(L_{1}+L_{2}\right)}{2 \pi} \ln \left\{\left[0.25+\left(\frac{h}{W_{1}}\right)^{2}\right]+\left[\left(\frac{W_{1}}{h}\right) \tan ^{-1}\left(\frac{2 h}{W_{1}}\right)\right]\right\} .
$$

Furthermore, the antenna input impedance can be calculated by combining circuit components in the equivalent circuit, and the results are plotted in Figure 3. The input impedance of the proposed 3D PILA generated from the CST simulation is also added to the equivalent circuit model curve for ease of comparison. A slight discrepancy is found between the modeled input impedance and the simulated antenna input impedance. In reality, the approximation equations used for PILA antenna to calculate the element values are derived by assuming uniform current distribution on the antenna. The tag antenna should be matched to the measured impedance of the RFID ASIC chip $Z_{c}^{\text {measurement }}=(26-j 163) \Omega[24]$ in order to achieve conjugate matching. Indeed, at $900 \mathrm{MHz}$, the modeled input impedance of the antenna is $Z_{\text {ant }}^{\text {modeled }}=(22.5-j 180) \Omega$, and the simulated impedance of the antenna is $Z_{\text {ant }}^{\text {simulated }}=(12.5-j 164) \Omega$. However, despite minor divergences, a reasonable agreement is observed and it shows that the proposed equivalent circuit model is valid to be used for the impedance analysis. 


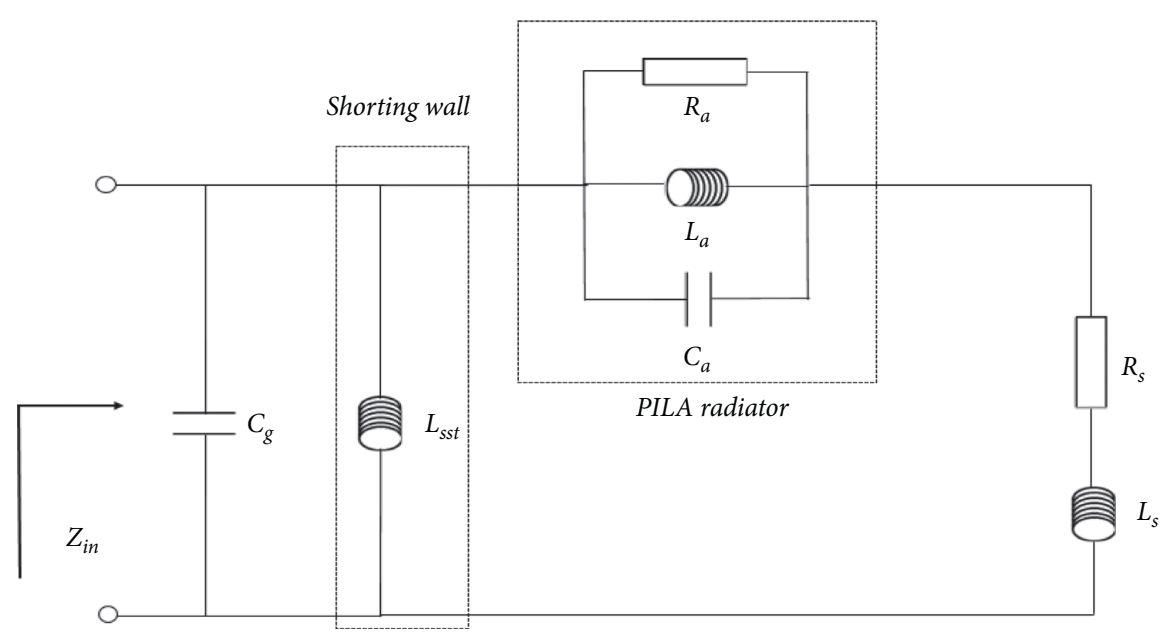

FIGURE 2: Equivalent circuit of the proposed 3D PILA tag antenna $\left(R_{a}=1380 \Omega, L_{a}=5.25 \mathrm{nH}, C_{a}=5.9 \mathrm{pF}, R_{s}=0.045 \Omega, L_{s}=14.84 \mathrm{nH}\right.$, $L_{\text {sst }}=29.68 \mathrm{nH}$, and $\left.C_{g}=0.15 \mathrm{pF}\right)$.

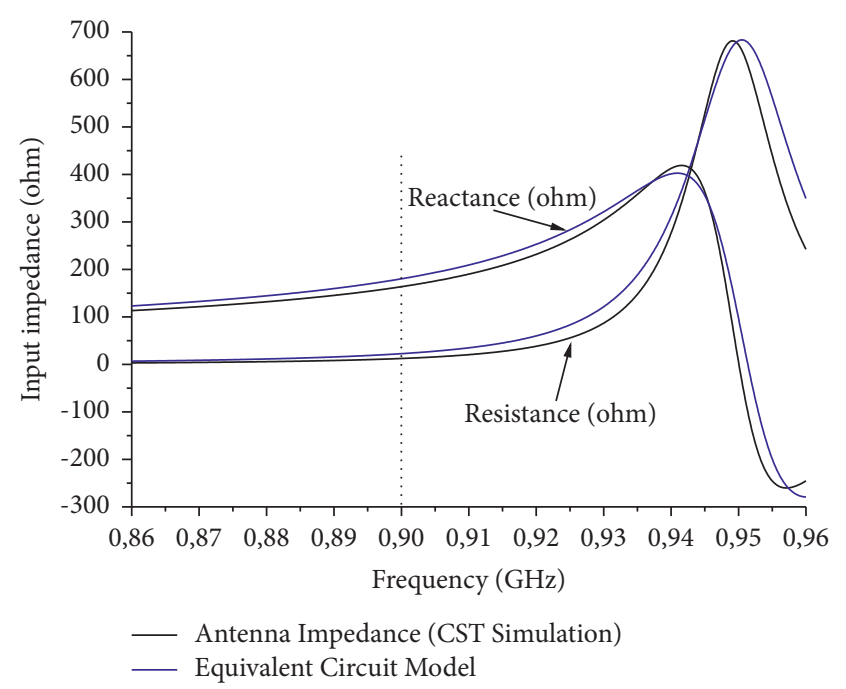

FIGURE 3: Simulated and modeled input impedances of the proposed 3D PILA tag antenna.

\section{Results and Discussion}

The proposed 3D PILA tag is placed on the center of a piece of $300 \times 300 \mathrm{~mm}^{2}$ metallic plate in simulations and measurements. Figure 4 shows the simulated and measured reflection coefficients of the proposed tag antenna. The simulated return loss of $20 \mathrm{~dB}$ is obtained at the frequency of $907 \mathrm{MHz}$ without the metallic plate. Good impedance matching was achieved at $900 \mathrm{MHz}$ for a $17.7 \mathrm{~dB}$ return loss with the metallic plate. It could be observed that the resonant frequency of the tag is stable and it is not affected much by the metallic object. By simply changing the length of the matching T-slot onto a radiating element, the return loss of the antenna can be tuned to match the impedance value of the chip.

The height of the tag $(h)$ is an important parameter in terms of resonant frequency, bandwidth, and antenna gain. By increasing the height of the top plate, the bandwidth is

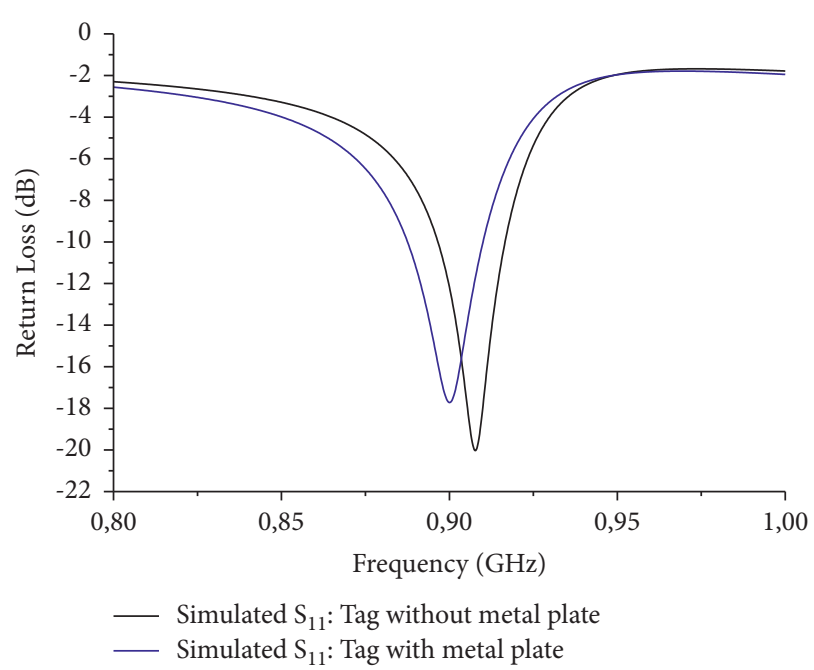

FIgUre 4: Simulated reflection coefficients of the proposed 3D PILA tag antenna.

increased but the reflection coefficient is decreased. The quality factor $Q$ is determined by the inverse of antenna bandwidth. Hence, the best way to increase antenna bandwidth (low $Q$ ) is to maximize the volume of the proposed 3D PILA tag. So, increasing the antenna area (antenna height) decreases the reflection coefficient. In addition, if we decrease the height of the top plate, the gain of the antenna decreases, and the intensity of the radiation pattern behind the ground plane increases. Therefore, the optimum height of the PILA antenna was $4 \mathrm{~mm}$.

Figure 5 depicts the simulated $3 \mathrm{D}$ radiation patterns at the resonant frequency of the prototype PILA antenna in free space and on a $30 \times 30 \mathrm{~cm}^{2}$ metal plate. Simulation results show that a tag antenna without a metallic plate has gain $1.98 \mathrm{~dB}$ at $905 \mathrm{MHz}$ and an antenna with metallic plate has gain $4.08 \mathrm{~dB}$ at $900 \mathrm{MHz}$. Therefore, the addition of the metallic plane is found to be useful to improve the antenna gain by strengthening the electromagnetic fields in the boresight direction $(+z$ direction $)$. 


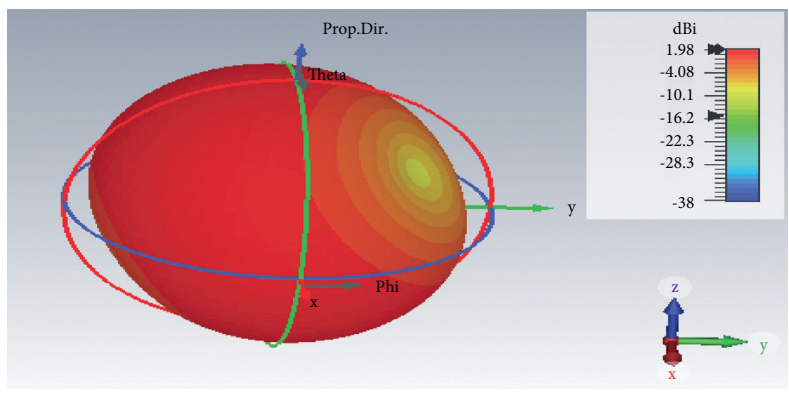

(a)

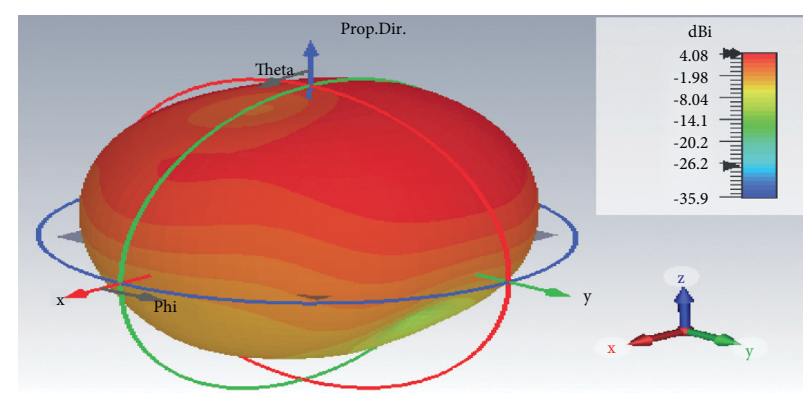

(b)

FIgURE 5: Simulated 3D radiation patterns of the proposed PILA tag antenna when it is placed (a) in the free space and (b) on the $30 \mathrm{~cm} \times 30 \mathrm{~cm}$ metal plate.

The simulated $E$ - and $H$-plane radiation patterns in polar form for the PILA antenna in free space and on the metal plate are shown in Figure 6. It can be observed that when the proposed tag antenna is placed on a $30 \times 30 \mathrm{~cm}^{2}$ metal plate, the direction of maximum radiation is changed. As could be expected, the back radiation of the antenna with metal is reduced with respect to the PILA antenna in free space due to the in-phase reflection properties of the metallic plate.

We characterized the performances of the tag in free space and on the metal plate. A procedure for the measurement of our PILA antenna is presented in [25]. Figure 7 shows the experimental setup in the anechoic chamber. In the measurement process, the tag and the horn antenna (reader) are placed face-to-face on a straight horizontal plane. The distance between the reader antenna and the PILA tag antenna is fixed to $d=55 \mathrm{~cm}$, while the transmitted power sent by the reader is varied gradually until the tag is activated. The tag is placed at the middle of a metal plate in the $x y$-plane with angle $\varphi=90^{\circ}$.

Figure 8 shows the minimum power versus frequency in free space and on a $30 \mathrm{~cm} \times 30 \mathrm{~cm}$ metal plate. In free space, the minimum power needed for generating a correct response to a command is approximately $4.5 \mathrm{dBm}$ at $901 \mathrm{MHz}$. The measured tag sensitivity increases to $9.9 \mathrm{dBm}$ at $897 \mathrm{MHz}$ when the tag is placed on the metal plate, which is less sensitive than that for free space. In the $x y$-plane $\left(\varphi=90^{\circ}\right)$, our tag in free space has a read distance of $3.6 \mathrm{~m}$ with the maximum reader output power approximately of $17.1 \mathrm{dBm}$.

Figure 9 shows the test setup for the measurement of the minimum tag turn on power in an anechoic chamber, where the sensitivity is measured by varying vertically the proposed tag along the $y$-axis. By observing the measured tag sensitivity, it can be seen from Figure 10 that the tag has the best sensitivity of $3.9 \mathrm{dBm}$ at $901 \mathrm{MHz}$ when the distance along the vertical $y$-axis is equal to $10 \mathrm{~cm}$. Therefore, in order to harness the much electromagnetic energy possible from the antenna, the 3D PILA tag must be positioned correctly facing the reader antenna.

To further verify the UHF tag antenna performance in free space and on metal, maximum reading range measurements for the tag were performed in a corridor environment. A procedure for the measurement of the tag is presented in $[26,27]$. The ThingMagic M6e embedded RFID reader module was used with a horn antenna to detect the tag which replies with its identification code. The power delivered varies between 5 and $31.5 \mathrm{dBm}(1.4 \mathrm{~W})$ through a computer interface within a frequency range going from 865.6 to $867.6 \mathrm{MHz}$ and the cable losses are about $0.8 \mathrm{dBm}$.

In order for a passive UHF RFID tag to be successfully read, the Received Signal Strength Indicator (RSSI) is used in order to provide a more accurate tag location. The read range and RSSI are measured in the European (EU) UHF RFID band in the direction of $\varphi=90^{\circ}$ in the $x y$-plane. Figure 11 shows the measured read range and RSSI when the tag antenna is placed in free space and on the metal plate in the direction of $\varphi=90^{\circ}$. For free space measurement, the maximum read distance of the tag is measured to be $6.3 \mathrm{~m}$ with $31.5 \mathrm{dBm}$ transmit power and the measured receiver sensitivity is $-69 \mathrm{dBm}$ at the frequency of $867 \mathrm{MHz}$. As depicted in Figure 11, the tag is able to achieve a maximum reading distance of $\sim 9.6 \mathrm{~m}$ when it is tested on a $30 \times 30 \mathrm{~cm}^{2}$ metallic plate, at the frequency of $867.5 \mathrm{MHz}$. However, when measuring the read performance in the xy plane, the PILA tag antenna is rotated $45^{\circ}$ clockwise about its own $z$ axis. The read range $\left(\varphi=45^{\circ}\right)$ increases to $11 \mathrm{~m}$ with RSSI $=-72 \mathrm{dBm}$ at $866.9 \mathrm{MHz}$ when the tag antenna is placed on a copper plate. Figure 12 shows the measured read distances in the boresight direction $\left(\theta=0^{\circ}, \varphi=0^{\circ}\right)$ in the $x y$ plane. The measured best read range of the tag is $18 \mathrm{~m}$ $(\mathrm{RSSI}=-74 \mathrm{dBm})$ with $31.5 \mathrm{dBm}$ transmit power at $867 \mathrm{MHz}$ when it is tested on a metallic plate.

Note that the use of Thingmagic M6 RFID reader in the 902-928 MHz band (US; FCC) can increase the reading distance of the proposed tag since our tag antenna operates around $900 \mathrm{MHz}$.

It is clear that our tag works very well in a real environment. However, the reason for this read range increase in corridor environment is attributed to constructive addition of a direct beam and reflected beams, perhaps from the wall and floor, each of which contains a weak indirect signal of the strong direct signal. Consequently, the metal plate is used as a backing reflector to reduce the rear radiation, improve the gain and directivity of the antenna in the front direction, and increase outdoor read ranges. 

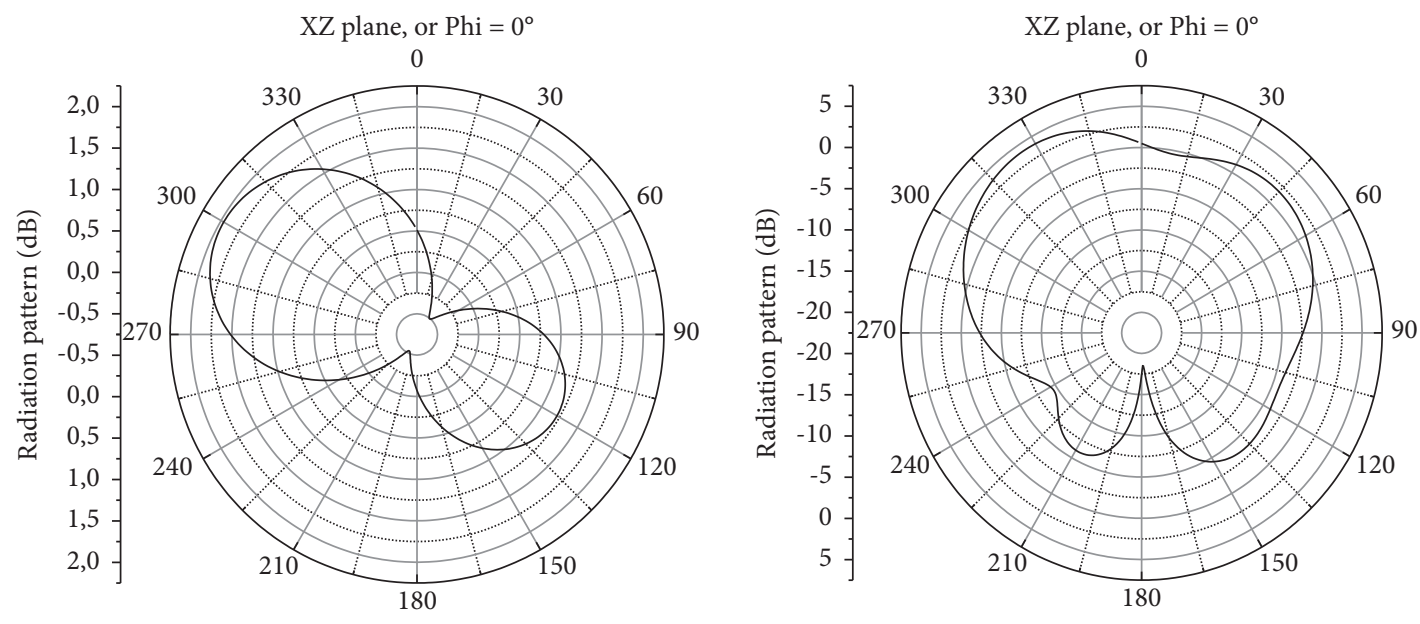

_- E-plane

_- E-plane
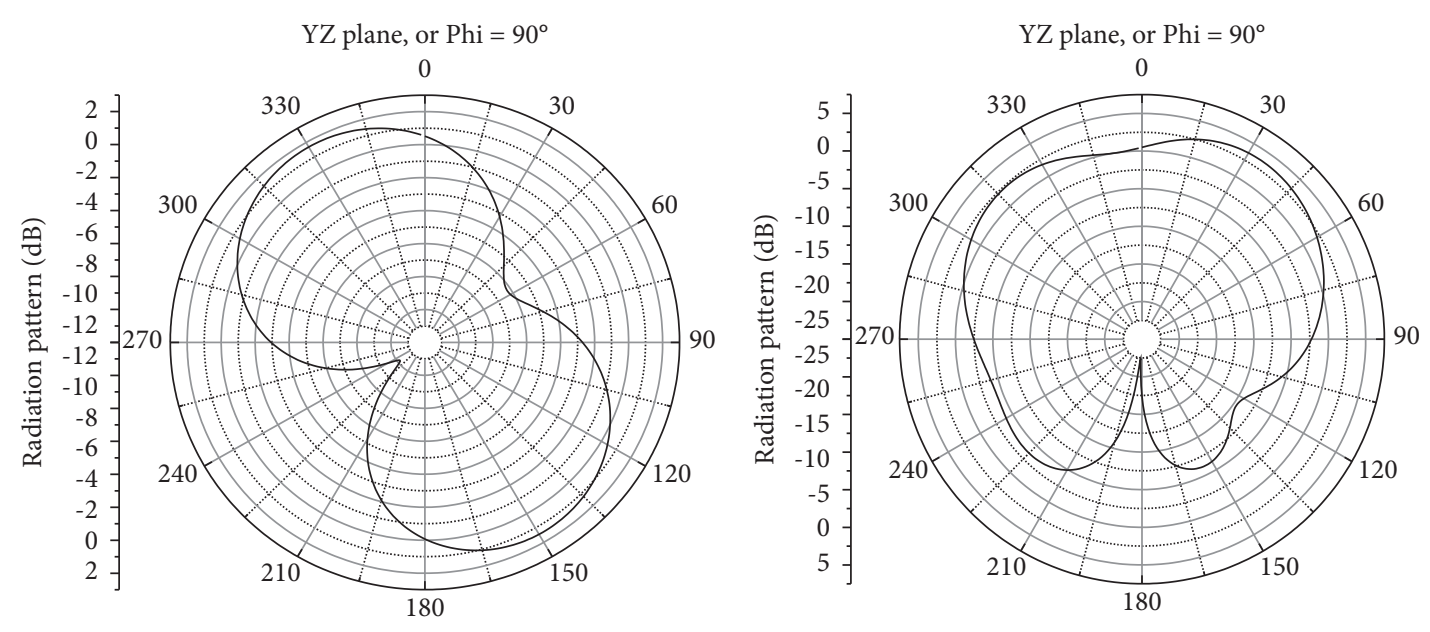

- H-plane

_ H-plane

(a)

(b)

Figure 6: Simulated radiation patterns of the proposed 3D PILA tag antenna when it is placed (a) in the free space and (b) on the $30 \mathrm{~cm} \times 30 \mathrm{~cm}$ metal plate.

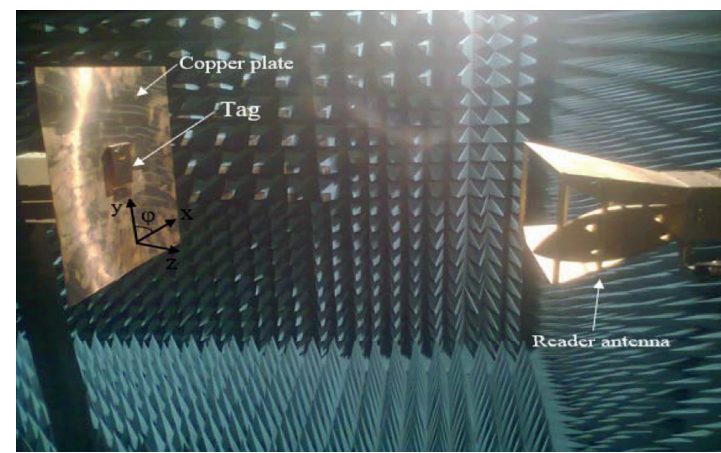

(a)

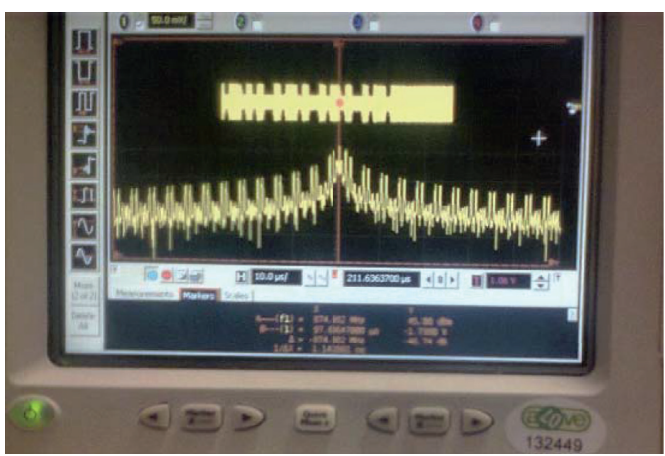

(b)

FIGURE 7: Tag measurement setup in the anechoic chamber for tag sensitivity measurements. (a) PILA tag range measurement. (b) Portion of the received tag response at $901 \mathrm{MHz}$. 


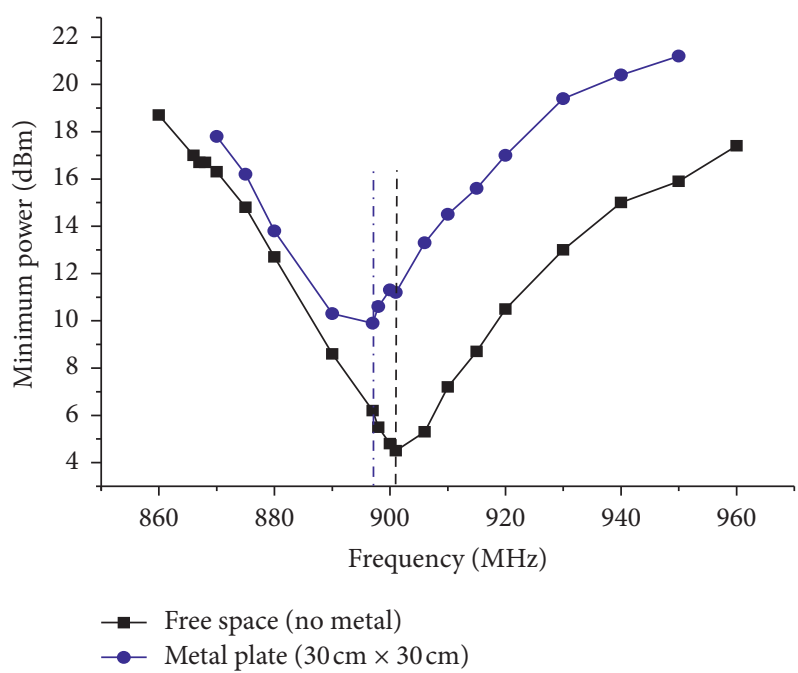

Figure 8: Far-field measurement $(d=55 \mathrm{~cm})$ : minimum power versus frequency when the tag antenna is placed in the free space and on the metal plate.

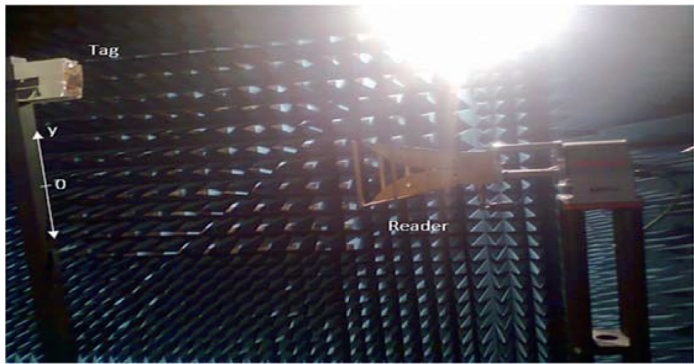

Figure 9: Test setup for the measurement of minimum tag turn on power when the tag is placed in the free space.

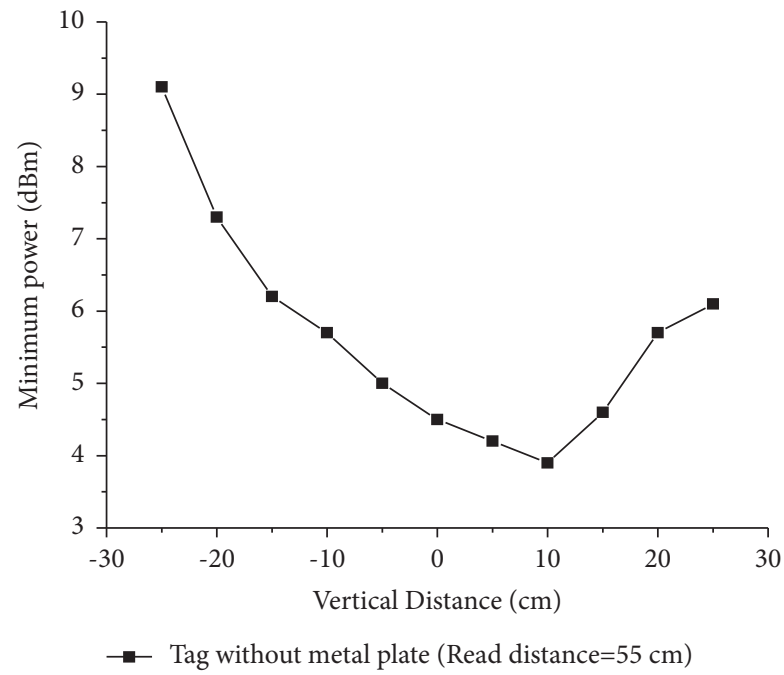

Figure 10: Minimum power vs. vertical distance when the tag antenna is placed in the free space.

The performance of the proposed 3D PILA is compared with other published metal-mountable UHF RFID tags in Table 2. With reference to the table, the tag in [28] is able to achieve a maximum read distance of $14.6 \mathrm{~m}$ in the outdoor environment but the tag size is larger than ours and it requires the use of two FR4 substrates and to be separated by an air layer to increase the bandwidth of the antenna. Similarly, with a large profile, the tag in [26] attains longer read distances than our proposed tag, which is able to reach $46.5 \mathrm{~m}$ in the corridor. Moreover, the tag uses a spiral- 


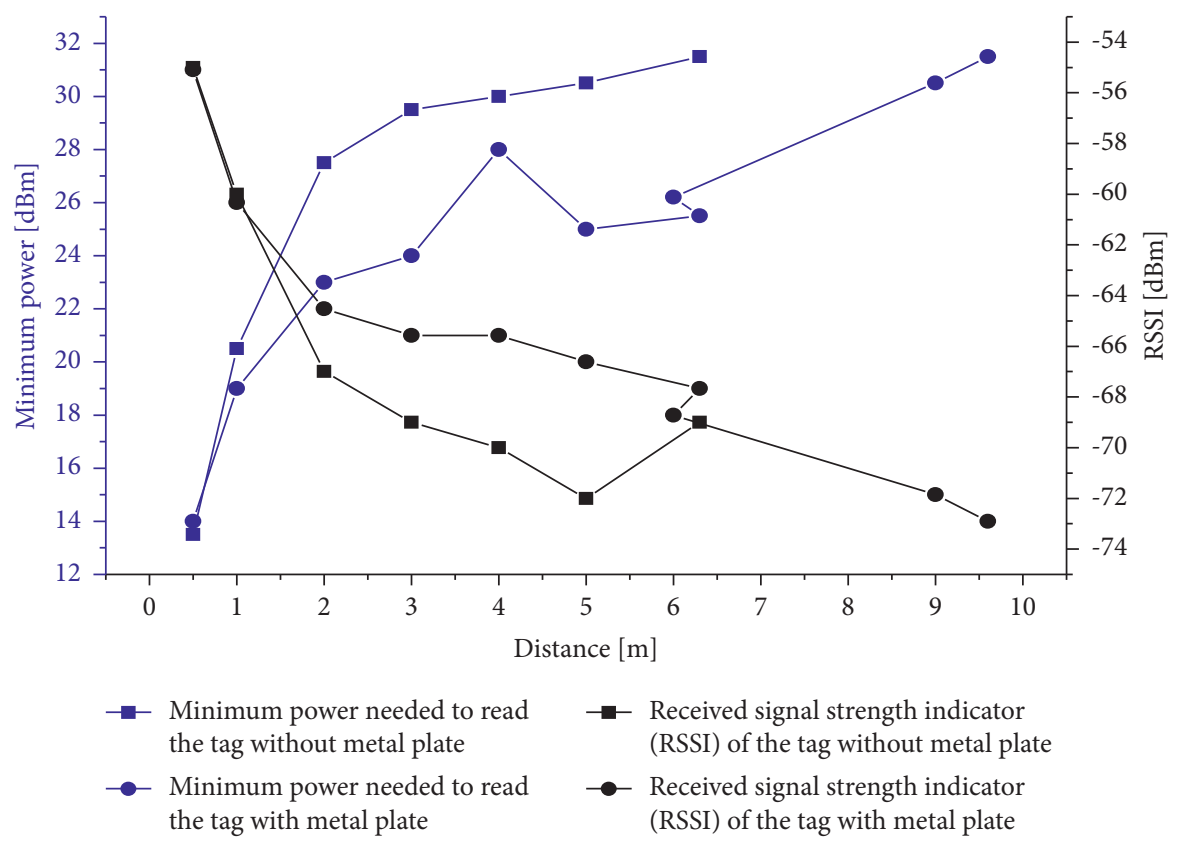

FIGURE 11: Read range and RSSI which are measured when the tag antenna is placed in the free space and on the metal plate $(30 \mathrm{~cm} \times 30 \mathrm{~cm})$ in the direction of $\varphi=90^{\circ}$ in the $x y$-plane.

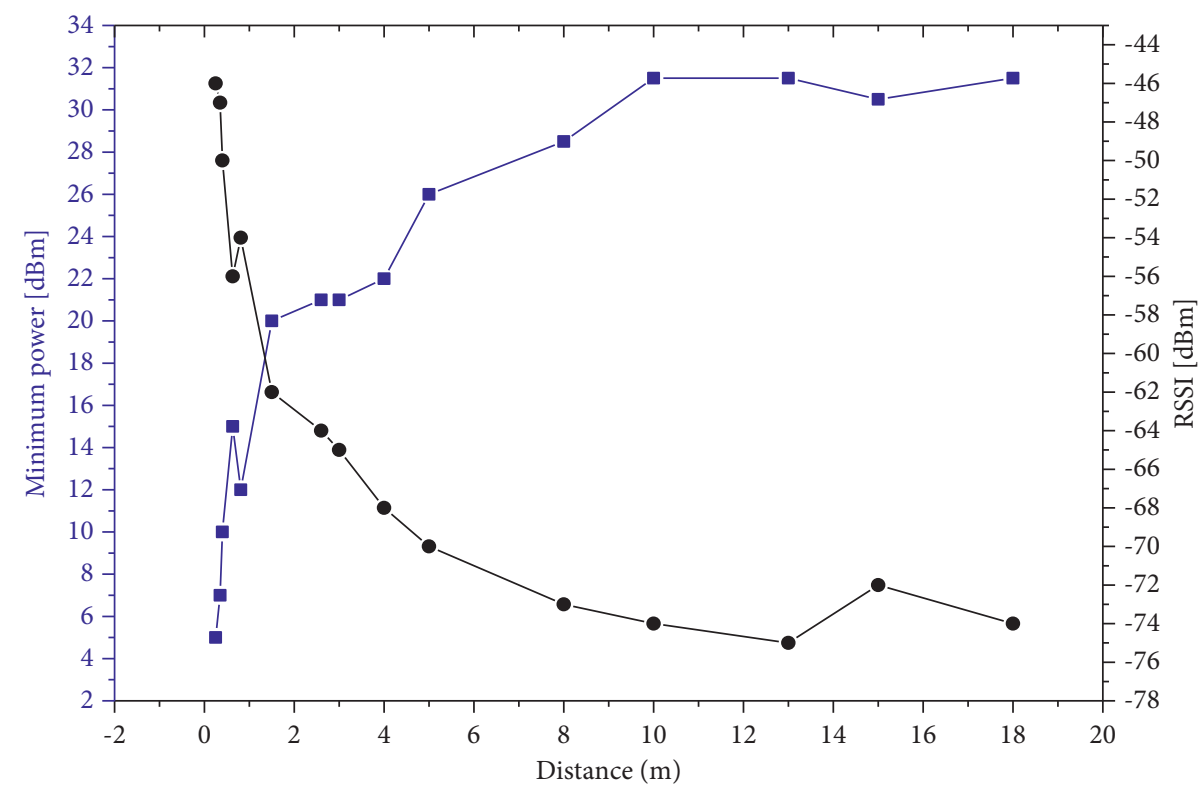

FIGURE 12: Read range and RSSI which are measured when the tag antenna is placed on the metal plate $(30 \mathrm{~cm} \times 30 \mathrm{~cm})$ in the direction of $\varphi=0^{\circ}$ in the $x y$-plane.

shaped artificial magnetic conductor (AMC) to increase the tag gain, which makes the fabrication processes very troublesome. Further, in order to increase the antenna gain and read range, the UHF RFID tag can be associated with a reflector plane as in [29] but this makes the antenna heavy and extremely large. In [30], with a reader transmitting power of $1.2 \mathrm{~W}$, the tag is only able to achieve the maximum read distance of $5 \mathrm{~m}$. In addition, the idea of designing the tag antenna using Hilbert curve structure for tagging large metallic objects is impractical to implement. For the case in
[31], the tag has almost the same size as ours with a size $88 \mathrm{~mm} \times 32 \mathrm{~mm} \times 3.2 \mathrm{~mm}$. The tag antenna mounted on the metallic surface is able to achieve a maximum read distance of $7.2 \mathrm{~m}$, but the read performance of the tag in free space has not been studied. Referring to Table 2 again, the tag in [14] is compact and flexible, but employing slots for miniaturization can complicate the design and fabrication process. Also, their achievable read distances inside the anechoic cabinet are shorter than ours. However, the read distances are also estimated in [14], which is able to reach $5.2 \mathrm{~m}$, when the tag 


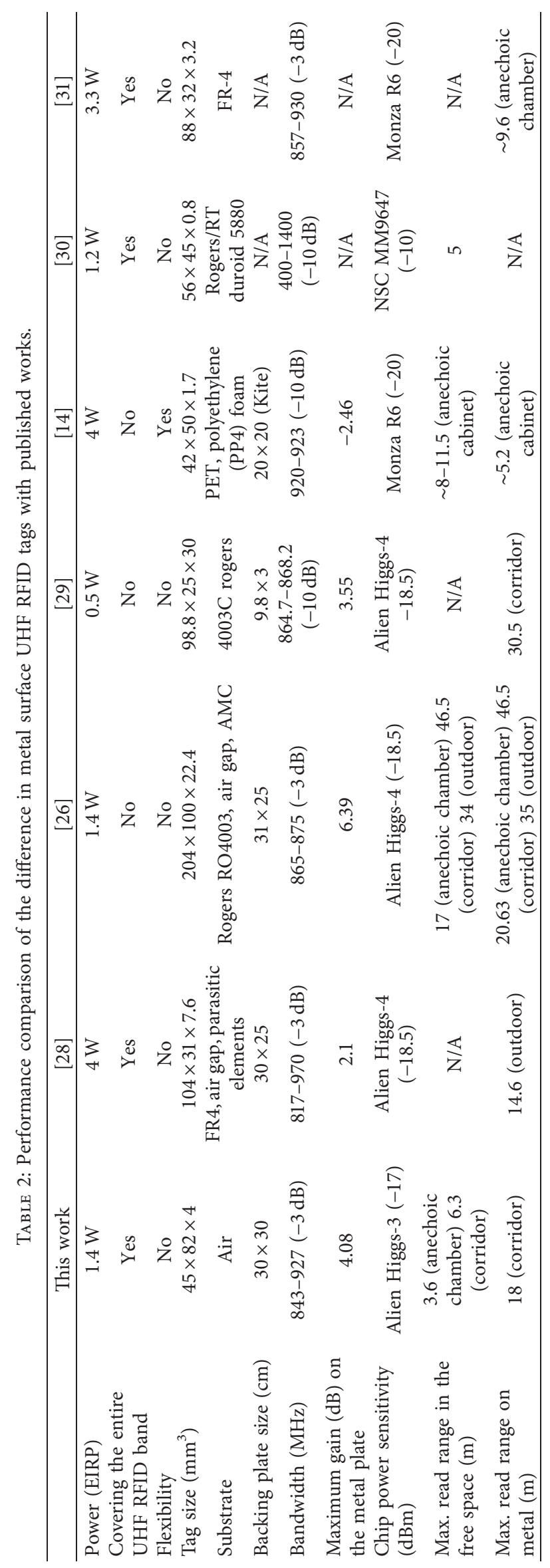


is placed on a metal plate. With a reasonable tag size, our proposed tag is able to achieve reasonable read distances in both free space and metallic objects. On the other hand, our tag is made using a copper sheet of a thickness of $1 \mathrm{~mm}$ and it does not need the use of the substrate. In addition, our proposed tag does not require the use of multiple shorting vias, parasitic elements, and meandered slotlines. It is not only much simple to design but it can also be easily manufactured, which is preferable for tracking metal objects of various IoT environments in indoor positioning systems. Therefore, our 3D PILA tag can easily be used in heavy industry and outdoor applications.

\section{Manufacturing Process}

The manufacturing process begins with sourcing all the parts, namely, copper sheet and plastic support. The second step in the process is to source the consumables such as adhesive and solder. Indeed, the antenna elements were made with a $1 \mathrm{~mm}$ copper sheet and the substrate of the whole proposed antenna is air. Plastic support is used in between the radiating element (patch antenna) and the ground plane. The next step is cutting the copper sheet by laser to obtain the adjacent antenna parts (Figure 1(c)). After cutting the antenna to the desired length, it will be folded to have the final 3D structure of our tag. Furthermore, soldering the IC to the structure and inserting the plastic backing constitute the final manufacturing step. However, the total cost for manufacturing per tag is no more than $\$ 1$ (USD).

\section{Conclusion and Future Work}

A novel design of a 3D PILA tag antenna for the UHF RFID system has been proposed for mounting on metallic objects. It is shown that by using two copper plates and separated by an air layer, the structure is insensitive to the presence of metallic objects, its gain can be increased, and the bandwidth covers all passive UHF RFID band. The T-slot is also applied to the design for adjusting the resistance and reactance of the antenna impedance. A simple and cost-effective method for fabrication is possible with this design while eliminating the need for vias and complicated multilayer structures. An equivalent circuit has been developed for analyzing the impedance characteristics of the tag antenna. Good agreement is found between the simulation and modeled data. Simulations and measurements have been conducted to demonstrate the tag performances to metallic and nonmetallic objects. The maximum read ranges of our proposed tag are $6.3 \mathrm{~m}$ in free space and $18 \mathrm{~m}$ when mounted on metal surfaces under real operating conditions (building hallway). When compared with some metal tags, our proposed tag is simple in structure and it is able to achieve reasonable read distances in free space and on metallic objects. The proposed antenna is a good candidate for RFID and IoT applications in real environments.

In future, we can design the Tag using metamaterial concepts [32-34] by placing a metamaterial slab above a PILA antenna (as a superstrate) to focus the signal in one direction to provide a long detection range.

\section{Data Availability}

The data used to support the findings of the study are included within the article.

\section{Conflicts of Interest}

The authors declare that there are no conflicts of interest regarding the publication of this paper.

\section{References}

[1] L. Brás, N. B. Carvalho, P. Pinho, L. Kulas, and K. Nyka, "A review of antennas for indoor positioning systems," International Journal of Antennas and Propagation, vol. 2012, Article ID 953269, 14 pages, 2012.

[2] G. Enriquez, S. Park, and S. Hashimoto, "Wireless sensor network and RFID fusion approach for mobile robot navigation," ISRN Sensor Networks, vol. 2013, Article ID 157409, 10 pages, 2013.

[3] M. Dhaouadi, M. Mabrouk, S. Tedjini, and A. Ghazel, "Magnetic antenna for near-field UHF RFID Tag," in Proceedings of the 18th International Conference on Microwave, Radar and Wireless Communications MIKON 2010, pp. 1-2, Vilnius, Lithuania, June 2010.

[4] M. Dhaouadi, M. Mabrouk, T. P. Vuong, A. C. de Souza, and A. Ghazel, "A capacitively-loaded loop antenna for UHF nearfield RFID reader applications," in Proceedings of the 2015 IEEE Radio and Wireless Symposium (RWS), pp. 193-195, San Diego, CA, USA, January 2015.

[5] J.-S. Kim, W. Choi, and G.-Y. Choi, "UHF RFID tag antenna using two PIFAs embedded in metallic objects," Electronics Letters, vol. 44, no. 20, pp. 1181-1182, 2008.

[6] A. A. Babar, T. Bjorninen, V. A. Bhagavati, L. Sydanheimo, P. Kallio, and L. Ukkonen, "Small and flexible metal mountable passive UHF RFID tag on high-dielectric polymerceramic composite substrate," IEEE Antennas and Wireless Propagation Letters, vol. 11, pp. 1319-1322, 2012.

[7] D. Kim and J. Yeo, "Dual-band long-range passive RFID tag antenna using an AMC ground plane," IEEE Transactions on Antennas and Propagation, vol. 60, no. 6, pp. 2620-2626, 2012.

[8] B. Gao and M. M. F. Yuen, "Passive UHF RFID packaging with electromagnetic band gap (EBG) material for metallic objects tracking," IEEE Transactions on Components, Packaging, and Manufacturing Technology, vol. 1, no. 8, pp. 1140-1146, 2011.

[9] L. Mo and C. Qin, "Planar UHF RFID tag antenna with open stub feed for metallic objects," IEEE Transactions on Antennas and Propagation, vol. 58, no. 9, pp. 3037-3043, 2010.

[10] H.-D. Chen and Y.-H. Tsao, "Low-profile meandered patch antennas for RFID tags mountable on metallic objects," IEEE Antennas and Wireless Propagation Letters, vol. 9, pp. 118121, 2010.

[11] F.-L. Bong, E.-H. Lim, and F.-L. Lo, "Flexible folded-patch antenna with serrated edges for metal-mountable UHF RFID tag," IEEE Transactions on Antennas and Propagation, vol. 65, no. 2, pp. 873-877, 2017.

[12] W.-H. Ng, E.-H. Lim, F.-L. Bong, and B.-K. Chung, "Folded patch antenna with tunable inductive slots and stubs for UHF tag design," IEEE Transactions on Antennas and Propagation, vol. 66, no. 6, pp. 2799-2806, 2018.

[13] F.-L. Bong, E.-H. Lim, and F.-L. Lo, "Compact orientation insensitive dipolar patch for metal-mountable UHF RFID tag 
design," IEEE Transactions on Antennas and Propagation, vol. 66, no. 4, pp. 1788-1795, 2018.

[14] S.-R. Lee, E.-H. Lim, F.-L. Bong, and B.-K. Chung, "Slotted folded patch antenna with double-T-slots for platform-insensitive UHF tag design," IEEE Transactions on Antennas and Propagation, vol. 67, no. 1, pp. 670-675, 2019.

[15] S.-R. Lee, E.-H. Lim, F.-L. Bong, and B.-K. Chung, "Highefficient compact folded-patch antenna fed by T-shaped L-probe for on-metal UHF RFID tag design," IEEE Transactions on Antennas and Propagation, vol. 68, no. 1, pp. 152-160, 2020.

[16] B. Mun, Y. Yoon, H. Lee, H.-Y. Lee, and B. Lee, "A compact dual-band RFID tag antenna mountable on metallic objects," International Journal of Antennas and Propagation, vol. 2015, Article ID 131908, 8 pages, 2015.

[17] J. Zhang and Y. Long, "A miniaturized via-patch loaded duallayer RFID tag antenna for metallic object applications," IEEE Antennas and Wireless Propagation Letters, vol. 12, pp. 1184-1187, 2013.

[18] A. Michel, V. Franchina, P. Nepa, and A. Salvatore, "A UHF RFID tag embeddable in small metal cavities," IEEE Transactions on Antennas and Propagation, vol. 67, no. 2, pp. 1374-1379, 2019.

[19] Alien Higgs-3 Tag Chip, “ALC-360-SOT (datasheet)," p. 4, 2017, https://www.alientechnology.com/download/higgs-3datasheet/.

[20] C.-W. Moh, F. L. Bong, B. K. Chung, and E.-H. Lim, "Miniature coplanar-fed folded patch for metal mountable UHF RFID tag," IEEE Transactions on Antennas and Propagation, vol. 66, no. 5, pp. 2245-2253, 2018.

[21] D. Kim and J. Yeo, "A passive RFID tag antenna installed in a recessed cavity in a metallic platform," IEEE Transactions on Antennas and Propagation, vol. 58, no. 12, pp. 3814-3820, 2010.

[22] Y.-H. Lee, E.-H. Lim, F.-L. Bong, and B.-K. Chung, "Compact folded C-shaped antenna for metal-mountable UHF RFID applications," IEEE Transactions on Antennas and Propagation, vol. 67, no. 2, pp. 765-773, 2019.

[23] W.-H. Ng, E.-H. Lim, F.-L. Bong, and B.-K. Chung, "E-shaped folded-patch antenna with multiple tuning parameters for onmetal UHF RFID tag," IEEE Transactions on Antennas and Propagation, vol. 67, no. 1, pp. 56-64, 2019.

[24] J.-H. Cho, H.-W. Son, S.-H. Jeong, W.-K. Choi, and C.-W. Park, "A flexible, wideband RFID tag antenna for metallic surfaces," in Proceedings of the 2012 IEEE International Symposium on Antennas and Propagation, pp. 1-2, Chicago, IL, USA, July 2012.

[25] M. Dhaouadi, M. Mabrouk, T. P. Vuong, A. C. De Souza, and A. Ghazel, "A broadband UHF tag antenna for near-field and far-field RFID communications," Radioengineering, vol. 23, no. 4, pp. 1026-1032, 2014.

[26] D. Hamzaoui, F. Djahli, T.-P. Vuong, T. Quynh Van Hoang, and G. Kiani, "High gain long-read range AMC-backed tag antenna for european UHF RFID applications," Microwave and Optical Technology Letters, vol. 58, no. 12, pp. 2944-2948, 2016.

[27] M. Dhaouadi, M. Mabrouk, T. Vuong, and A. Ghazel, "Magnetic Tag antenna for UHF near-field and far-field RFID applications," International Journal on Communications Antenna and Propagation (IRECAP), vol. 5, no. 2, pp. 119123, 2015.

[28] A. Hamani, M. C. E. Yagoub, T.-P. Vuong, and R. Touhami, "A novel broadband Antenna design for UHF RFID tags on metallic surface environments," IEEE Antennas and Wireless Propagation Letters, vol. 16, pp. 91-94, 2017.

[29] L. Benmessaoud, T.-P. Vuong, M. C. E. Yagoub, and R. Touhami, "A novel 3-D tag with improved read range for UHF RFID localization applications," IEEE Antennas and Wireless Propagation Letters, vol. 16, pp. 161-164, 2017.

[30] M. Alibakhshi-Kenari, M. Naser-Moghadasi, R. Ali Sadeghzadeh, B. S. Virdee, and E. Limiti, "Dual-band RFID tag antenna based on the Hilbert-curve fractal for HF and UHF applications," IET Circuits, Devices and Systems, vol. 10, no. 2, pp. 140-146, 2016.

[31] H. Bouazza, A. Lazaro, M. Bouya, and A. Hadjoudja, "A planar dual-band UHF RFID tag for metallic items," Radioengineering, vol. 29, no. 3, pp. 504-511, 2020.

[32] F. Martín, "Metamaterials for wireless communications, radiofrequency identification, and sensors," ISRN Electronics, vol. 2012, Article ID 780232, 29 pages, 2012.

[33] M. Alibakhshikenari, B. S. Virdee, L. Azpilicueta et al., "A comprehensive survey of metamaterial transmission-line based antennas: design, challenges, and applications," IEEE Access, vol. 8, pp. 144778-144808, 2020.

[34] N. Ripin, E.-H. Lim, F.-L. Bong, and B.-K. Chung, "Miniature folded dipolar patch with embedded AMC for metal mountable tag design," IEEE Transactions on Antennas and Propagation, vol. 68, no. 5, pp. 3525-3533, 2020. 